\title{
The Association between Maternal Mortality and Non-Medical factors in African Countries
}

\author{
${ }^{*}$ P. Lalthapersad-Pillay, EO Udjo \\ University of South Africa, South Africa \\ *lalthp@unisa.ac.za
}

\begin{abstract}
The medical expertise to treat to complications arising from pregnancy and childbirth has not spared girls and women in developing countries from dying of such conditions. Developing countries account for the bulk of the global share of maternal deaths with complications of pregnancy and childbirth being the leading cause of death in young women aged between 15 and 49. Sub-Saharan Africa is responsible for nearly three-fifths of all global maternal deaths which have saddled it with notoriously high levels of maternal mortality ratios, a concern that has been red-flagged internationally and regionally. Most studies on maternal mortality in Africa have been confined to an examination of factors impinging on maternal mortality from both medical and socioeconomic standpoints for individual country's based on survey data. Our study differs from others as it employs logistic regression to look at the association between non-medical factors and maternal mortality nationally for all African countries. Whilst the results from the logistic regression suggests that there is no statistically significant relationship between any of the variables and maternal mortality, the odds ratio for Human Development Index (HDI) and Gross National Income per capita (GNI) imply that African countries with low HDI are about three time more likely to have high maternal mortality compared to high HDI countries. Similarly, African countries with low GNI are about five times more likely to have high maternal mortality compared to high GNI countries.
\end{abstract}

Keywords: Maternal mortality ratio, maternal deaths, Africa, socio-economic factors, Millennium Development Goals, Human Development Index, Gross National Income

\section{Introduction and background}

Estimates attest that every minute and a half, a woman dies from complications related to pregnancy and childbirth and that the risk factor is higher among poor women, those who are rurally-based and adolescents (WHO, 2013). Globally in 2000 deaths due to pregnancy and childbearing accounted for $14 \%$ of deaths in the reproductive cohort (WHO, 2009). A worrisome fact is that $99 \%$ of the more than half a million maternal deaths every year occur in developing countries and complications of pregnancy and childbirth are the leading cause of death in young women aged between 15 and 49. In 2008, nearly three -fifths of maternal deaths (204 000) took place in sub-Saharan Africa (WHO et al., 2010). Even though most African countries have managed to reduce their maternal mortality ratios since 1990, with a small exception of increases in some countries, they have remained unacceptably high, surpassing both the global level of 260 and that for developing countries of 290 . Thus it runs the risk of reversing gains made in the fields of public health in these countries (WHO, 2009). The purpose of our study is to examine the association between nonmedical factors and maternal mortality in African countries, given the high levels of maternal mortality in many African countries where little change has been recorded. We begin with an overview of maternal mortality and highlight global and regional trends. Secondly, we examine the association between maternal morality and the Human Development Index (HDI), Gross National Income per capita (GNI), secondary school enrolment ratio, contraceptive prevalence, average age at first marriage as given by the singulate mean age at marriage (SMAM) and the Total Fertility Rate (TFR) through the use of both bivariate analysis and a logistic regression.

MDG Goal Five deals with an improvement in maternal health and its target is a three-quarters reduction in the maternal mortality ratio (MMR) between 1990 and 2015 which is unlikely to be met in many African countries even though all have recorded reductions, with a small exception of increases in some countries (UN, 2013a). There is just one year left for the realisation of all MDG targets but regardless of MDG 5 not being met, maternal health has been identified as one of the health indicators in the Post-2015 Development Agenda that must be prioritised. The post-2015 development agenda can be viewed as an 
attempt to bring the MDGs to its logical completion by noting its successes, tackling unresolved challenges and honing in on side-lined issues (UN, 2013b). The High Level Panel of Eminent Persons in their report, A New Global Partnership: Eradicate Poverty and Transform Economies through Sustainable Development pronounce on six principles that underscore ending poverty and promoting sustainable development. The Panel came up with 12 goals and 54 targets, 16 which focus specifically on health. Goal 4 which is the health goal has five targets and two pertain to girls and women, the one seeking to reduce maternal mortality and the other to provide universal access to sexual and reproductive health services and rights (Horton, 2013). One example of a potential impact envisaged by the Post-2015 Development Agenda is that by 2030, the world would have 4.4 million more women who would otherwise have died during pregnancy or childbirth, labelling it a social ill that has to be eradicated (Machel et al., 2013). Goal 2 seeks to empower girls and women and achieve gender equality. It comprises three national targets and the one target is to end child marriage (UN, 2013b).

\section{Literature Review}

Pregnancy and childbearing carry health risks that affect women in their reproductive years and which have dire consequences for most women in Africa (WHO, 2009). The World Health Organization's (1977) International Classification of Diseases (ICD-9) defines a maternal death "as the death of a woman while pregnant or within 42 days of termination of pregnancy, irrespective of the duration and the site of the pregnancy, from any cause related to or aggravated by the pregnancy or its management, but not from accidental or incidental causes". The number of maternal deaths in a population rests on the risk of mortality stemming from a single pregnancy or a single live birth and the number of pregnancies or births that women of reproductive age undergo (WHO et al., 2010). Maternal or (obstetric) deaths can be defined as either direct or indirect. A direct obstetric death is one due to complications of pregnancy, delivery or the postpartum period, including abortion complications. Indirect obstetric deaths are those due to existing medical conditions that are made worse by the pregnancy or delivery (Winikoff et al., 1987). In 1987 the Safe Motherhood Initiative highlighted the apathy of developing countries to the issue which has subsequently been labelled 'a neglected tragedy' and 'the dividing barrier between developed and developing countries' (Hogan et al., 2010; UNFPA, 2009; Rosenfield \& Maine, 1985). The fragmented efforts in tracking progress in most countries can be blamed on the paucity of maternal mortality estimates owing to the incorrect assigning of the cause of death, outdated and incomplete date, an absence of registration of deaths, and the fact that deaths that occur at home are unrecorded (WHO et al., 2010). Encumbering this issue is the fact that two-thirds of the world's population have to contend with an absence of death registration and for one-third there is incorrect assigning of the cause of death (Graham et al., 2008). Fear on the part of unmarried women and the need to avoid culpability or to conceal deaths due to abortion also spur the underreporting of deaths (Graham, 1991).

A worrisome fact is that $99 \%$ of the more than half a million maternal deaths every year occur in developing countries and complications of pregnancy and childbirth are the leading cause of death in young women aged between 15 and 49. Thus it runs the risk of reversing gains made in the fields of public health in these countries (WHO, 2009). On average about three-quarters of maternal deaths that take place in developing countries can be blamed on direct obstetric causes and one-quarter on indirect causes (McCarthy \& Maine, 1992). Haemorrhage, infection, squeal of illicit induced abortion, pregnancyinduced hypertension and obstructed labour/raptured uterus account for most obstetric deaths (Maine, 1987). The most important indirect cause of maternal deaths is malaria, anaemia and malnutrition (Maine, 1987; Royston \& Armstrong, 1989). Viral hepatitis (hepatic or infective hepatitis) and anaemia are the main indirect causes of maternal mortality in sub-Saharan Africa and are caused by inadequate nutrition, mainly protein-deficiency, thus rendering them poverty-induced diseases (Graham, 1991; Kwast \& Stevens, 1987). Inadequate preventable and curative health care services in developing countries undermine the prevention of pregnancies, as well as the early diagnosis and effective treatment of pregnancy complications (McCarthy \& Maine, 1992). An examination of global and regional maternal mortality estimates provides a clearer picture of overall gains made thus far. Despite interventions to reduce maternal mortality globally, the MMR fell by $47 \%$ over the past two decades which is below the $75 \%$ set target required (UN, 2013b). The most recent estimates of maternal deaths come from Hogan et al. (2010) who put the decline in maternal deaths worldwide from 526300 in 1980 to 342900 in 2008 whilst the WHO et al., (2010) put the decrease at 576000 in 1990 to 358000 in 2008. In 2008, 99\% of maternal deaths occurred in developing countries, with nearly three -fifths of maternal deaths (204 000) 
taking place in sub-Saharan Africa. HIV/AIDS accounted for $9 \%$ of maternal deaths in sub-Saharan Africa (WHO et al., 2010).

The maternal mortality ratio (MMR), which is the number of deaths per 100, 000 live births, fell globally from 422 per 100000 live births in 1980 to 251 in 2008 (Hogan et al., 2010). The WHO et al. (2010) puts the decline from 400 per 100000 live births in 1990 to 260 in 2008. Developing regions had a MMR of 290 compared to14 in developed countries. Among the developing regions, sub-Saharan Africa had the highest MMR at 640 maternal deaths per 100000 live births which is $221 \%$ higher than the level for developing countries. In the absence of HIV/AIDS, the MMR for sub-Saharan Africa would be pegged at the lower level of 580 per 100, 000 live births (WHO et al., 2010). For the rest of study, we focus only on the MMR as it is the indicator that is tracked by the MDG Goal 5. The extent of maternal mortality in African countries is examined in greater detail. Even though most African countries have managed to reduce their maternal mortality ratios since 1990, with a small exception of increases in some countries, they have remained unacceptably high, surpassing both the global level of 260 and that for developing countries of 290. The steep maternal mortality ratios in Africa, especially sub-Saharan Africa has been red-flagged both internationally and regionally, a challenge that has been noted by the African Union $(\mathrm{AU})$, leading it to push member states to undertake measures to address the issue at country level.

Table 1 shows that in 2008 MMR among fifty African countries varied widely with low levels of 60 and 36 in Tunisia and Mauritius respectively whilst countries such as Guinea-Bissau, Chad, Somalia, Liberia, Burundi, Sierra Leone, Central African Republic, Nigeria, Mali and Niger had MMR in excess of 800 (WHO et al., 2010). The MDG target requires an average of 5.5\% annually from the 1990 levels and tracking progress in maternal mortality has been slow or non-existent and for most countries. The global average percentage decline over the period 1990 to 2008 was $2.3 \%$, a situation that has led many international agencies to conclude that meeting the MDG target a forlorn situation in most countries (WHO et al., 2010; UNFPA, 2009). In the African continent, only three countries had annual percentage declines of $5.5 \%$ or more, twenty-three countries had annual percentage declines of $2 \%$ to $5.5 \%$ and fifteen countries had annual percentage declines of less than 2\% (WHO et al., 2010). Based on our estimates of the 2015 targets shown in Table 1, we see that nine countries require reductions ranging between $10 \%$ to $49 \%$ and forty countries require reductions exceeding $50 \%$. The overall reductions that country's still have to meet paint a bleak picture of the state of reproductive health in many African states.

Table 1: The status of MMR for African countries as per MDG 5

\begin{tabular}{lllll}
\hline Country & $\begin{array}{l}\text { MMR } \\
\mathbf{1 9 9}^{\mathbf{1}}\end{array}$ & $\begin{array}{l}\text { MMR } \\
\mathbf{2 0 0 8}\end{array}$ & $\begin{array}{l}\text { MDG } \\
\text { Target } \\
\mathbf{2 0 1 5}^{\mathbf{3}}\end{array}$ & $\begin{array}{l}\text { Overall \% reduction still required } \\
\text { to achieve MDG target } \\
\mathbf{2 0 0 8 - 2 0 1 5}^{\mathbf{2}}\end{array}$ \\
\hline Equatorial Guinea & 1000 & 280 & 250 & -10.7 \\
Eritrea & 930 & 280 & 232.5 & -17.0 \\
Egypt & 220 & 82 & 55 & -32.9 \\
Morocco & 270 & 110 & 67.5 & -38.6 \\
Cape Verde & 230 & 94 & 57.5 & -38.8 \\
Tunisia & 130 & 60 & 32.5 & -45.8 \\
Ethiopia & 990 & 470 & 247.5 & -47.3 \\
Algeria & 250 & 120 & 62.5 & -47.9 \\
Rwanda & 1100 & 540 & 275 & -49.1 \\
Mauritius & 72 & 36 & 18 & -50.0 \\
Benin & 790 & 410 & 197.5 & -51.8 \\
Gambia & 750 & 400 & 187.5 & -53.1 \\
Senegal & 750 & 410 & 187.5 & -54.3 \\
Mozambique & 1000 & 550 & 250 & -54.5 \\
Ghana & 630 & 350 & 157.5 & -55.0 \\
Malawi & 910 & 510 & 227.5 & -55.4 \\
Guinea & 1200 & 680 & 300 & -55.9 \\
Niger & 1400 & 820 & 350 & -57.3 \\
\hline
\end{tabular}




\begin{tabular}{|c|c|c|c|c|}
\hline Angola & 1000 & 610 & 250 & -59.0 \\
\hline Madagascar & 710 & 440 & 177.5 & -59.7 \\
\hline Libyan Arab Jamahiriya & 100 & 64 & 25 & -60.0 \\
\hline Comoros & 530 & 340 & 132.5 & -61.0 \\
\hline Uganda & 670 & 430 & 176.5 & -61.0 \\
\hline Cote d'Ivoire & 690 & 470 & 172.5 & -63.3 \\
\hline Mali & 1200 & 830 & 300 & -63.9 \\
\hline Mauritania & 780 & 550 & 195 & -64.5 \\
\hline Burkina Faso & 770 & 560 & 192.5 & -65.6 \\
\hline $\begin{array}{l}\text { Democratic Republic of } \\
\text { Congo }\end{array}$ & 900 & 670 & 225 & -66.4 \\
\hline Sierra Leone & 1300 & 970 & 325 & -66.5 \\
\hline Nigeria & 1100 & 840 & 275 & -67.3 \\
\hline Burundi & 1200 & 970 & 300 & -69.1 \\
\hline Djibouti & 370 & 300 & 300 & -69.2 \\
\hline Guinea-Bissau & 1200 & 1000 & 300 & -70.0 \\
\hline Cameroon & 680 & 600 & 170 & -71.7 \\
\hline United Republic of Tanzania & 880 & 790 & 220 & -72.2 \\
\hline Liberia & 1100 & 990 & 275 & -72.2 \\
\hline Chad & 1300 & 1200 & 325 & -72.9 \\
\hline Central African Republic & 880 & 850 & 220 & -74.1 \\
\hline Gabon & 260 & 260 & 65 & -75.0 \\
\hline Namibia & 180 & 180 & 45 & -75.0 \\
\hline Somalia & 1100 & 1200 & 275 & -77.1 \\
\hline Zambia & 390 & 470 & 97.5 & -79.3 \\
\hline Congo & 460 & 580 & 115 & -80.2 \\
\hline Kenya & 380 & 530 & 95 & -82.1 \\
\hline Lesotho & 370 & 530 & 92.5 & -82.5 \\
\hline Botswana & 83 & 133 & 20.75 & -84.4 \\
\hline Swaziland & 260 & 420 & 65 & -84.5 \\
\hline South Africa & 230 & 410 & 57.5 & -86.0 \\
\hline Zimbabwe & 390 & 790 & 97.5 & -87.7 \\
\hline
\end{tabular}

Sources: WHO et al. [2010] $]^{1 \& 2}$

Authors' own estimates ${ }^{3 \& 4}$

It is this disconcerting picture that grasped the attention of the African Union (AU) and led to the introduction of the Campaign for Accelerated Maternal and Mortality (CARMMA) and the AU's tacit acknowledgement that not only are maternal mortality and under-five mortality huge development problems that confront Africa, but that the levels were intolerably high. The Fourth Session of the African Union (AU) Conference of Ministers of Health was held in Addis Ababa in May 2009 under the theme "Universal Access to Quality Health Services: Improve Maternal, Neonatal and child Health" set in motion the CARMMA campaign. The Campaign was launched under the slogan "Africa Cares: No woman should die while giving life" and the fifteenth Ordinary Session of the African Union Assembly that was held in Kampala, Uganda in July 2010, under the theme "Maternal, Infant and Child Health and Development in Africa" endorsed CARMMA. The Assembly drafted a list of Action on Maternal, New-born and Child Health and Development in Africa by 2015 that Heads of State and governments committed to uphold (Department of Health, 2012). The link between socioeconomic factors and maternal mortality has been widely examined. The state of health of individuals is influenced by social, economic and environmental determinants and as for most diseases, death is a more likely outcome for the poor than for the rich (UN, 2013a). The Safe Motherhood Initiative prompted a renewed focus on the determinants of maternal mortality in terms of causes and risk, especially the socioeconomic dimensions. However, 
McCarthy \& Maine (1992:28) caution that the association between socioeconomic factors and maternal mortality is "not automatic or direct".

The literature linking socioeconomic variables and maternal mortality is vast and include transportation issues, physical distance from facilities, the socioeconomic status of women, women's decision-making power, cultural, social, behavioural factors, the level of gender equality, the reproductive health regime at country-level, women's health standing, reproductive status in terms of age and parity, and the link between poverty and maternal mortality (Maine, 1987; Royston \& Armstrong,1989; Germain,1987; McMarthy \& Maine, 1992; Ronsman \& Graham, 2006; Fortney, 1985; Walker et al.,1985). Studies conducted have tended to show that that economic growth, improvements in per capita income, education, age at marriage, Contraceptive Prevalence Rate (CPR) and decline in the Total Fertility Rate (TFR) have assisted in bringing down MMR (Ronsman \& Graham., 2006; Hogan et al., 2010; WHO et al., 2010; Koblinsky et al., 2006; Filippi et al., 2006; Jain, 2011; Radkar \& Parasurman, 2007). Regression analyses examining the bearing of socioeconomic and demographic factors on maternal mortality have been conducted at individual country level. Kwast \& Liff (1988) conducted a logistic regression to determine factors associated with maternal mortality in Addis Ababa, Ethiopia and treated antenatal care, occupation and income as risk factors for maternal mortality. The study obtained odds ratio of 2.5 for unbooked women as opposed to those that received antenatal care, odds ratio of 3 for students and maids as opposed to housewives, and odds ratios of between 3 and 5 for those earning less than US $\$ 25$ monthly, compared to those earning in excess of US\$150. A study that focused on socioeconomic status and maternal mortality, utilized the Bangladesh Maternal Health Services and Maternal Mortality Survey 2001 and cross-tabulated maternal mortality during 1998-2000 by economic indicator and women's education. However, the study yielded no significant association and it is plausible that findings could have been compromised by the use retrospective data on maternal mortality (Rahman et al., 2009).

A study by Rahman et al. (2009) looked at the association between maternal mortality and demographic, programmatic and socioeconomic factors. The study utilized longitudinal data on 143,000 pregnancy outcomes during 1982 - 2002 from the Matlab Demographic Surveillance System in Bangladesh. The study found that only old age was a significant risk factor. In terms of the variation of maternal mortality with socioeconomic factors, they found in their bivariate analysis that maternal mortality is negatively associated with both the women's and her husband's education, and with their household space. Furthermore, risks for maternal mortality were higher for first pregnancies and women that have low levels of education and low socioeconomic status. Studies conducted in the US and the Matlab study found that risks for maternal mortality among teenagers is not due to physiological factors but to the manner in which socioeconomic factors contribute to higher risks of childbearing (Rahman et al., 2009). Dersarkissian et al. (2013) examined whether maternal mortality and socioeconomic, demographic and population-health explanatory factors could be correlated with maternal mortality in forty-nine African countries for the years 1990, 1995, 2000 and 2005. They found that lower Gross Domestic Product [GDP] and female enrolment in primary schools but higher HIV prevalence, neonatal mortality rate and total fertility rate were associated with higher maternal mortality. They concluded that improved socioeconomic, demographic and health factors foster improved maternal health outcomes in Africa. Jaleel \& Goli (2013) looked at factors associated with the decline in maternal mortality in India using both time series and cross-sectional data. Regression analysis showed that per capita state net domestic product, poverty ratio, female literacy rate, infant mortality rate and total fertility rate are statistically significantly associated with the decline in maternal mortality in India. They concluded that socioeconomic and demographic factors have a stronger statistically significant association with the maternal mortality ratio than the likelihood of deliveries taking place in health care facilities.

Pertinent to the African continent is the association between child marriage and MMR as research shows that it is contributes to the tally of maternal deaths. Child marriage which is defined as marriage before the age of 18 is most common in African and Asian countries and is tied to cultural and religious norms. Besides transgressing against human rights, it also disempowers girls (UNFPA, 2012; IPPF, 2006, UNICEF, 2001). Pregnancy-related complications are the leading cause of mortality in girls aged 15-19 in low income countries and is often the cause of permanent morbidity (UN, 2013b). Thirty-four per cent of the girls around the world, excluding China, are married by the age of 18 and eleven per cent marries before the age of 15 years (UNICEF, 2013). Estimates on the prevalence of child marriage shows that it amounts to $42 \%$ for Africa as a whole and exceeds $60 \%$ in parts of East and West Africa (UNICEF, 2005). Child marriages normally take place in low income, rural areas and among lowly-educated girls and where 
employment opportunities are low for women (Raj \& Boehmer, 2013). Marrying young restricts educational attainment, carries a higher risk of maternal death and of being subjected to violence and the likelihood of experiencing poverty (UN, 2013a). Contraceptive use is also least among adolescent wives. Child marriage initiates early sexual activity and early pregnancy which carry multiple health consequences as young brides are physically immature. Young brides are at risk for maternal and child morbidities (for example, delivery complications, fistula, low birth weight, malnutrition) and maternal and infant mortality (Raj, 2010; Raj \& Boehmer, 2013). Despite obstetric fistula being treatable and preventable, it is rife in poor communities in Africa and Asia and affects almost 2 million young girls and women (UNFPA, 2003; ICRW, 2013). Raj \& Boehmer (2013) in their study examined the association between rates of child marriages and maternal and infant mortality, non-utilization of maternal health services and HIV nationally for 79 nations and found that higher rates of girl child marriage are associated with higher rates of maternal and infant mortality and non-utilization of maternal health services, but not HIV. These findings suggest that a $10 \%$ increase in child marriages in a country is associated with a 3\% increase in a country's infant mortality rate, a $3 \%$ increase in national fertility rate and a $70 \%$ increase in their maternal mortality rate, as well as a $10 \%$ reduced likelihood of using a skilled birth attendant. We plot the MMR for 2008 for certain African countries against the percentage of girls' first marriage before the age of 18 for the period 2000 to 2011(UNFPA, 2012). Data on child marriages was only available for a few countries.

Figure 1: Percentage of child marriages in selected African countries

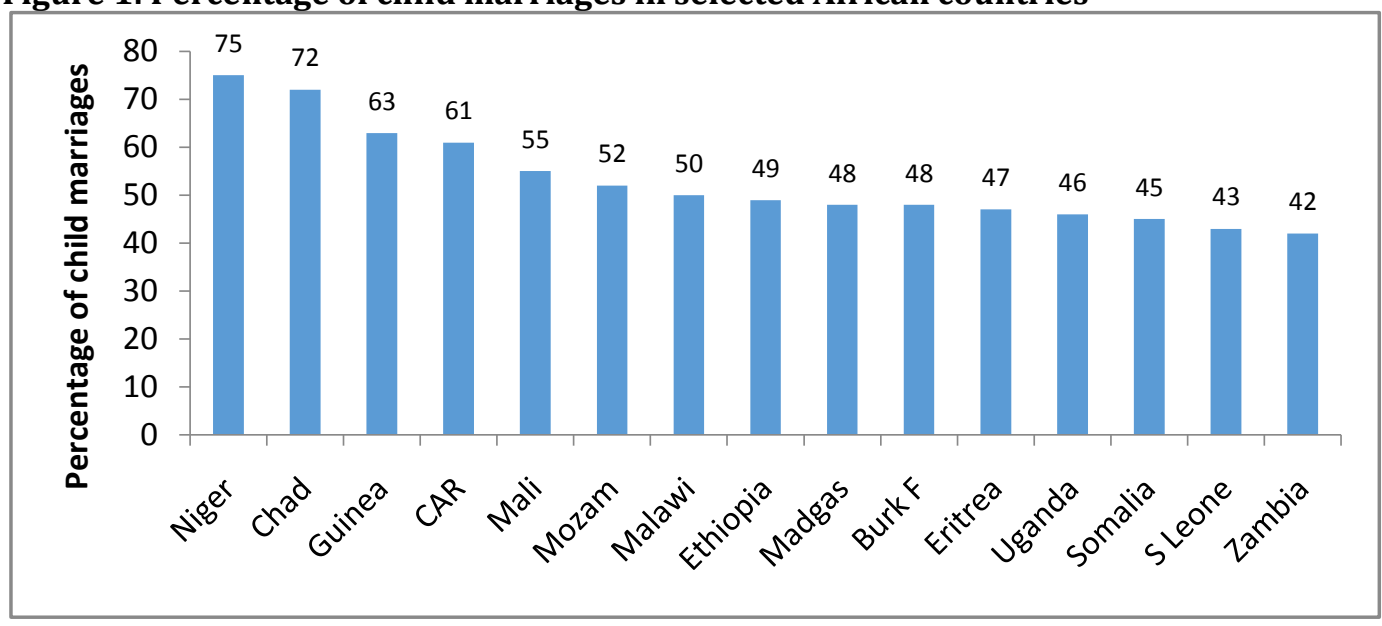

Source:Derived fom (UNFPA, 2012a).

Figure 2: Relationship of Maternal mortality ratio and percentage of child marriages in selected African countries

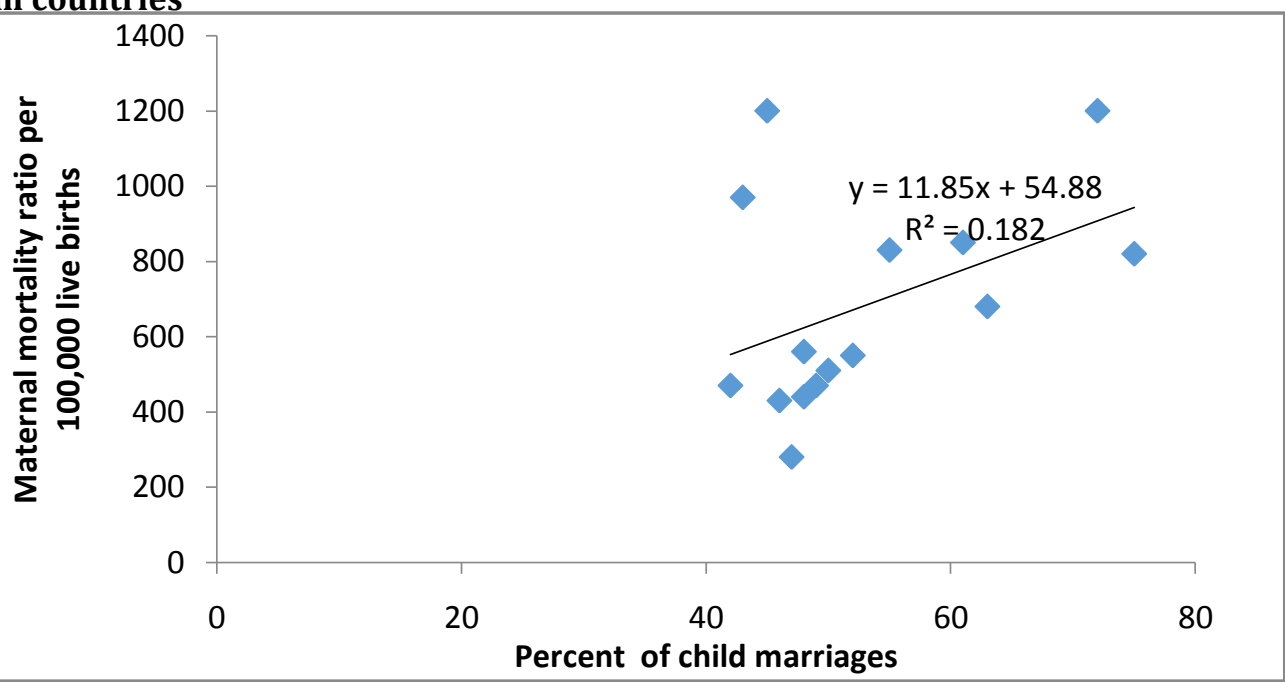

Source: Authors' own work derived from (UNFPA, 2012a). 
The bar chart in Figure 1 shows that for seven of the countries, over $50 \%$ of girls married before the age of 18 years with Niger having the highest percentage of child marriages and Zambia the lowest. The scatter plot in Figure 2 indicates that there is a correlation between a country's level of MMR and the proportion of child marriages ( $\mathrm{r}=0.43$ ). If one excludes the outliers (Somalia and Sierra Leone), that the correlation between MMR and the proportion of child marriages is even stronger $(r=0.84)$. The scatter plot in Figure 2 indicates that a one year reduction in the age at first marriage among women who married before the age of 18 years is associated with a $12 \%$ increase in the maternal mortality ratio.

A Contextualization of the study: Most studies on maternal mortality in Africa have been confined to an examination of the medical factors underlying it, or the influence of socioeconomic and demographic factors at individual country level based on survey data, or the correlation between maternal mortality and socioeconomic factors at a national level based on time-series analyses. Our study differs from others as it makes use of logistic regression to look at the association between non-medical factors and maternal mortality nationally for all African countries. A crucial point to note is that the influence of non-medical factors on maternal mortality operates indirectly through its impact on the direct determinants of maternal mortality. We look at only a limited number of variables that are deemed to have a marked presence in African countries, namely, the Human Development Index (HDI), Gross National Income per capita (GNI), the singulate mean age at marriage (SMAM), contraceptive prevalence rate, the gross secondary school enrolment ratios for girls, the total fertility rate (TFR) and the Labour Force Participation Rate (LFPR). The HDI is an index that captures three dimensions of human development - a long and healthy life, educational attainment and a decent standard of living (UNDP, 2013). GNI per capita is the average income per citizen and is measured in dollar terms. Contraceptive prevalence entails the use of any contraceptive method. Average age at first marriage is given by the singulate mean age at marriage (SMAM). The labour force participation rate (LFPR) is the proportion of a country's working age population that engages in the labour market, either by working or actively looking for work, expressed as a percentage of the working population (UNDP, 2013). The total fertility rate (TFR) is the number of children a woman would have if she survived up to age fifty and experienced the current age specific fertility rates. Data on HDI, GNI per capita and LFPR was obtained from the 2013 Human Development Report. Data on contraceptive prevalence rate and the TFR was acquired from UNFPA's 2012 State of World's Population Report. Data on SMAM was obtained from the Population Bureau website. Data on gross school enrolment ratios was obtained from the World Bank Development Indicators.

\section{Methodology}

The study employed bi-variate and multivariate methods of analysis. The bi-variate method entailed a scatter plot of maternal mortality ratios (dependent variable) with each non-medical factor included in this study [independent variables] to determine whether or not there is an association between the level of maternal mortality and each non-medical factor in African countries. Values of the spearman's correlation coefficient, $r \geq 0.5$ determined from the regression equation of the scatter plot of maternal mortality ratio and each non-medical factor is indicative of an association between maternal mortality and the non-medical factor. If $r$ was $\geq 0.5$ for a non-medical factor, that factor was then included in the multiple regression analysis. Since bi-variate methods can only examine the relationship between two variables at a time and do not control for different levels of other independent variables, a multi-variate analysis was deemed necessary. Although the dependent variable (maternal mortality ratio) is a continuous variable, for sample and standard error considerations, due to considerations about sample size and standard errors, the variable was converted to a dichotomous variable 0 , for low levels of maternal mortality and 1 for high levels of maternal mortality ratio. This was done to minimise standard error values since the sample size for this study is small, that is, only fifty. Employing the usual linear regression model would have generated high numbers of empty cells. In view of this, the logistic regression model was undertaken. The logistic regression model attempted to estimate the probability of an African country having a high maternal mortality ratio given certain levels (high or low) of nonmedical factors. The regression equation based on Hosmer and Lemesho (2000) may be expressed as:

$$
\operatorname{Prob}(M M R h)=\frac{1}{1+e^{-\left(B_{0}+B_{1 X 1}+B_{2 \times 2}+B_{n X n}\right)}}
$$

Where Prob (MMRh) is the probability of a country having a high maternal mortality ratio, $M M R h=1$ if the maternal mortality ratio was $\geq 500, M M R h=0$ if maternal mortality was $<500$. $e=$ base of the natural 
logarithm, $\mathrm{B}_{0}=$ constant, and $\mathrm{B}_{1 \ldots \mathrm{n}}=$ estimated regression coefficients for each of the independent variables coded 1 if the values of the variable were categorised as low and 0 if the values of the variable were categorised as high with the reference category being 0 . The categorisation of each of the independent variables was as follows.

We categorised the different variables into high and low. GNI Low is 110 US\$-1879 US\$ and High is 1880 US\$-21715 US\$; TFR Low is $1.6 \%-4.3 \%$ and High is $4.4 \%-6.3 \%$; Contraceptive Prevalence rate Low is $3 \%-29 \%$ and High is $30 \%-76 \%$; SMAM Low is 17.6 years -21.3 years and High is 21.4 years- 31.2 years; Gross secondary school enrolment ratios Low is $4.9 \%-33.2 \%$ and High is $33.3 \%-119.4 \%$; HDI Low is 0.304-0.439 and High is $0.440-0.769$; LFPR Low is $15 \%-49.9 \%$ and High is $50.0 \%-88.2 \%$. Two logistic regression models (Model 1 and Model 2) were used in the analysis. Model 1 examined the separate effect of each of the independent variables on the probability of a country having a high level of maternal mortality. Model 2 examined the combined effects of the independent variables on the probability of a country having a high level of maternal mortality. The analysis tested for correlation in the independent variables and it was found that there was a high correlation between SMAM and HDI, Secondary school enrolment and SMAM and gross Secondary School enrolment with TFR. In view of this, the independent variables included in Model 2 were HDI, GNI, Contraceptive prevalence and TFR having excluded SMAM and secondary school enrolment.

\section{Results and Discussion}

The results in Model 1 seem to suggest that there is a statistically significant positive relationship between low levels of HDI, GNI, contraceptive prevalence and high levels of maternal mortality ratio $(p<0.05)$ as well as a statistically significant negative relationship between low levels of TFR and high maternal mortality ratio $(\mathrm{p}<0.05)$ in African countries. In Model 2, there was no statistically significant relationship between any of the independent variables in the model and levels of maternal mortality after controlling for other independent variables in the model $(p>0.05)$. Note that while in Model 1 , the sign of the coefficient for contraceptive prevalence is positive, the sign is negative in Model 2 which is counter intuitive (low levels of contraceptive prevalence associated with low levels of maternal mortality. Although the results in Model 2 were not statistically significant, the odds ratio for HDI and GNI imply that African countries with low HDI are about 3 times more likely to have high maternal mortality than countries with high HDI. Similarly, African countries with low GNI are about 5 times more likely to have high maternal mortality than countries with high GNI. The low value of Nagelkerke R ${ }^{2}$ in Model $2(0.434)$ suggests that other variables not included in the regression analysis may be important in the probability of having a high level of maternal mortality in African countries (that is, unobserved heterogeneity). The bi-variate analysis results of the correlation between MMR and the different variables are shown in Table 2. The table indicates that there is a high positive correlation $(r>0.5)$ between the level of maternal mortality ratio and the total fertility rate in African countries, that is, the higher the level of total fertility rate, the higher the level of maternal mortality ratio in African countries. The table also suggests that there is a high negative correlation between the level of maternal mortality ratio and GNI, HDI, secondary school gross enrolment ratios, contraceptive prevalence rate and SMAM in African countries, that is, the higher the values of each of these variables, the lower the value of the maternal mortality ratio.

Table 2: Summary of scatter plot of maternal mortality ratios with non-medical factors in African countries

\begin{tabular}{lll}
\hline Factors & $\begin{array}{l}\text { Number } \\
\text { countries }\end{array}$ & $\begin{array}{l}\text { of } \\
\text { coefrelation } \\
\text { coeient }\end{array}$ \\
\hline TFR & 49 & 0.6830 \\
LFPR & 50 & 0.2862 \\
GNI & 50 & -0.5664 \\
HDI & 49 & -0.7712 \\
Gross secondary school enrolment & 50 & -0.7075 \\
ratios for girls & & \\
Contraceptive prevalence rate & 50 & -0.6066 \\
SMAM & 48 & -0.5933 \\
\hline
\end{tabular}

Source: Authors' own work. 
Table 3: Logistic Regression of Levels of maternal mortality ratio with non-medical factors in African countries

\begin{tabular}{|c|c|c|c|c|c|}
\hline \multirow{2}{*}{$\begin{array}{l}\text { Independent } \\
\text { Variables }\end{array}$} & \multicolumn{2}{|l|}{ Model 1} & \multicolumn{2}{|l|}{ Model 2} & \multirow{2}{*}{$\begin{array}{l}\text { Odds } \\
\text { ratio }\end{array}$} \\
\hline & Coefficient & Significance & Coefficient & Significance & \\
\hline \multicolumn{6}{|l|}{ HDI } \\
\hline \multicolumn{6}{|l|}{ Low (RF) } \\
\hline High & $1.846(0.638)^{*}$ & 0.004 & $1.122(1.327)^{*}$ & 0.179 & 3.072 \\
\hline \multicolumn{6}{|l|}{ GNI } \\
\hline \multicolumn{6}{|l|}{ Low (RF) } \\
\hline High & $3.098(1.096)^{*}$ & 0.005 & $1.554(1.327)^{*}$ & 0.241 & 4.732 \\
\hline \multicolumn{6}{|l|}{$\begin{array}{l}\text { Contraceptive } \\
\text { prevalence }\end{array}$} \\
\hline Low (RF) & $1.186(0.601)^{*}$ & 0.048 & $-1.033(0.989)^{*}$ & 0.296 & 0.356 \\
\hline \multicolumn{6}{|l|}{ High } \\
\hline \multicolumn{6}{|l|}{ SMAM } \\
\hline \multicolumn{6}{|l|}{ Low (RF) } \\
\hline High & $1.286(0.617)^{*}$ & 0.025 & & & 0.356 \\
\hline \multicolumn{6}{|l|}{ TFR } \\
\hline \multicolumn{6}{|l|}{ Low (RF) } \\
\hline High & $-2.639(0.841)^{*}$ & 0.002 & $-2.092(1.160)^{*}$ & 0.71 & 0.123 \\
\hline \multicolumn{6}{|l|}{$\begin{array}{l}\text { Gross sec school } \\
\text { enrolment }\end{array}$} \\
\hline \multicolumn{6}{|l|}{ Low (RF) } \\
\hline High & $1.168(0.648)$ & 0.072 & & & \\
\hline \multicolumn{6}{|l|}{ LFPR } \\
\hline \multicolumn{6}{|l|}{ Low (RF) } \\
\hline High & -0.747 & $(0.621)^{*}$ & 0.229 & & \\
\hline Constant & & & $-0.627(1.444)^{*}$ & 0.664 & \\
\hline Nagelkerk R ${ }^{2}$ & & & 0.434 & & \\
\hline
\end{tabular}

Source: Authors' own work

* Standard errors in parenthesis

The findings of the study from the bivariate analysis showed that there is a high positive correlation $(\mathrm{r}>$ 0.5 ) between the level of maternal mortality ratio and the total fertility rate in African countries, that is, the higher the level of total fertility rate, the higher the level of maternal mortality ratio in African countries. The study also found that there is a high negative correlation between the level of maternal mortality ratio and GNI, HDI, secondary school gross enrolment ratios, contraceptive prevalence rate and SMAM in African countries, that is, the higher the values of each of these variables, the lower the value of the maternal mortality ratio. In terms of the results for the logistic regression, although the results in Model 2 were not statistically significant, the odds ratio for HDI and GNI imply that African countries with low HDI are about 3 times more likely to have high maternal mortality than countries with high HDI. Similarly, African countries with low GNI are about 5 times more likely to have high maternal mortality than countries with high GNI. In the following section we revisit very briefly the general research on socioeconomic and demographic factors that support the said influence on maternal mortality. The finding that low GNI are associated with higher maternal mortality is evocative of the fact that countries with a higher standard of living afford their citizens better development outcomes. It also points to the active role that governments' play in uplifting the welfare of its citizens through appropriate policy interventions and wise public spending (Bailey, 2012). Income per head has a bearing on maternal mortality in terms of either nutritional well-being of mothers, as well as physical proximity to health care facilities and affordability of health care.The finding that low HDI is associated with higher maternal mortality must be contextualized in terms of how the Index is composed, namely, that it includes both income and non-income aspects of human development and the fact that economic growth does not automatically translate into economic development and the well-being of people. Therefore, the implementation of pro-poor policies that seek to enhance the capabilities of people through investment in education and training, nutrition, health and job opportunities and decent work are the cornerstones of development (UNDP, 2013). 
The literature on the benefits of women's education on maternal mortality point to spinoffs such as later marriage, effective contraception usage, reduced fertility, a healthier disposure, good maternal nutrition, affordability and timely acquiring of medical care (Royston \& Armstrong, 1989). In a recent study in Matlab, it was found that the use of skilled obstetric care at home or more skilled facilities is significantly and positively associated with household economic conditions and that maternal mortality is significantly lower among educated women compared to women with no education (Rahman et al., 2009). Regarding age at marriage, research shows that girls who marry very young tend to have early and closely spaced pregnancies. Statistics show that of the 16 million girls who give birth every year, about $90 \%$ are already married (UNFPA, 2012). Childbearing at an early age pushes up both maternal mortality and child mortality, especially for mothers under the age of 20 , the latter situation being contingent on the fact that pregnancies at younger age are likely to be first pregnancies and first pregnancies have higher risks for maternal mortality (Rahman, et al., 2009). Turning to the issue of child marriage, despite attempts to halt child marriages in countries where it is prevalent, there are no signs of it tapering off. Ending child marriage would require that sexual, reproductive and maternal health programmes do not just cater for older married women, but are also tailored to meet the needs of adolescents and child brides (UN, 2013b).

Universal access to sexual and reproductive rights (SRHR) is an imperative in every society. Family planning initiatives as well as access to safe abortions are some measures to reduce the number of children women bear which ultimately impacts on both total fertility and maternal mortality. It is estimated that 222 million women in the world do not have the means to prevent pregnancy as they are denied access to modern methods of contraception. This causes 80 million unplanned pregnancies, 30 million unplanned births and 20 million unsafe abortions every year. Access to SRHR is also especially low amongst adolescents (UN, 2013a). Even though contraceptive prevalence rate rose worldwide during the 20year period [1990 and 2010] from 55\% to 63\%, there were wide disparities. In 2010, it was less than $20 \%$ in 23 countries, all of which were in Africa. A notable increase from $12 \%$ to $33 \%$ occurred in Eastern Africa whilst western and central Africa has seen little change with contraceptive prevalence only rising from a modest $7 \%$ to $14 \%$ in twenty years. Countries like Chad, Mali, Mauritania and Niger likely is where contraceptive prevalence matters most given the forecasted threefold surge in population that they are likely to experience. Studies show that contraceptive prevalence has an important bearing on fertility in that a rise of 15-17 percentage points decreases fertility by one birth per woman (Cleland \& Shah, 2013). Other studies estimate that every $\$ 1$ spent on modern contraception would save $\$ 1.40$ in maternal and new-born health care (Singh \& Darroch, 2012). These findings bolster the call made at the 2012 London Summit on Family Planning for renewed efforts to extend contraception usage in countries where its levels are exceeding low (UN, 2013a).

Maternal health still features prominently in the Post-2015 Development Agenda and going forward, there has to be clear articulation of what measures and support are required to effect change in those countries plagued by high levels of maternal mortality. This is the key role for which government as a stakeholder must seek to address by providing the necessary budgetary and institutional resources to this end. Another stakeholder that is important are the health departments in different countries which need to ensure that hospitals and clinics are adequately resourced with the medical staff and support structures to not only to deal with maternal deaths but to provide family planning measures to avoid unwanted pregnancies. There is no doubt that current and reliable statistics lie at the heart of the problem which requires that national bodies charged with the collection of statistics are able to function effectively. Also, the results of the study raises questions about the importance of socioeconomic and demographic factors in maternal mortality given the vast interest that has been generated in such factors over the years and the reminder that they need to be heeded to bring down the number of maternal deaths. Thus, the dilemma confronting those in the public health sphere rests on determining where the focus should be, namely, on medical factors or the socioeconomic ones, or do both matter but in differing degrees.

\section{References}

Bailey, R. (2012). How do you measure development? Available at: http://www.blog.inasp.info/how_do_you_measure_development

Dersarkissian, M., Thompson, C. A. \& Arah, O. A. (2013). Time series analysis of maternal mortality in Africa from 1990 to 2005. Journal of Epidemiology and Community Health, 67(12), 992-998. 
Cleland, J. \& Shah, I. H. (2013). The contraceptive revolution: focussed efforts are needed. The Lancet, 381[9878], 1604-1606.

Department of Health. (2012). South Africa's National Strategic Plan for a Campaign on Accelerated Reduction of Maternal and Child Mortality (CARMMA). Pretoria: Department of Health.

Filippi, V., Ronsmans, C., Campbell, O. M., Graham, W. J., Mills, A. \& Borghi, J. (2006). Maternal health in poor countries: broader context and call for action. The Lancet, 386, 1542-1545.

Fortney, J. (1985). Maternal mortality in Indonesia and Egypt. Paper presented at the WHO Interregional Meeting on the Prevention of Maternal Mortality. Geneva, 11-15 November.

Germain, A. (1987). Reproductive health and dignity: choices by Third World women. Paper presented at the International Conference on Better Heath for Women and Children through Family Planning, Nairobi, 5-9 October.

Graham, W. J. (1991). Maternal Mortality: levels, trends and data deficiencies. Disease and Mortality in Sub-Saharan Africa, R.G. Feachem, R.G. \& D.T. Jamison (Eds). Oxford University Press. Washington, 101-115.

Graham, W. J., Foster, L. B., Davidson, L., Hauke, E. \& Campbell, O. M. R. (2008). Measuring Progress in Reducing Maternal Mortality. Best Practice and Clinical Obstetrics and Gynaecology, 22(3), 425445.

Hogan, M. C., Foreman, K. J., Naghavi, M., Ahn, S. Y., Wang, M., Makela, S. M., Lopez, A. D., Lozano, R. \& Murray, J. L. (2010). Maternal mortality for 181 countries, 1980-2008: a systematic analysis of progress towards Millennium Development Goal 5. The Lancet, 375(9726), 1609-1623.

Horton, R. (2013). Offline: Ensuring healthy lives after 2015. The Lancet. Available at: http://www.thelancet.com.

Hosmer, D. \& Lemesho, S. (2000). Applied logistic regression. New York: John Wiley and Sons.

The International Center for Research on Women (ICRW). (2013). Child marriage facts and figures. Available at: http://www.ICRW.org

International Planned Parenthood Federation (IPPF). (2006). Ending child marriage. A guide for global policy action. Available at: htttp: //www.ippf.org

Jain, A. K. (2011). Measuring the effect of fertility decline on the maternal mortality ratio. Studies in Family Planning, 42(4), 247-260.

Jaleel, A. C. P. \& Goli, S. (2013). What is the cause of the decline in maternal mortality in India? Evidence from time series and cross-sectional analyses. Paper presented at the XXXVII International Population Conference, Busan, Korea, 26-31 August.

Koblinsky, M., Matthews, Z., Hussein, J., Mavalankar, D., Mridha, M. K. \& Anwar, I. (2006). Going to scale with professional skilled care. Lancet, 368, 1377-1386.

Kwast, B. E. \& Stevens, J. A. (1987). Viral hepatitis as a major cause of maternal mortality. International Journal of Gynaecology and Obstetrics, 25, 99-106.

Kwast, B. E. \& Liff, J. M. (1988). Factors associated with maternal mortality in Addis Ababa, Ethiopia, International Journal of Epidemiology, 17(1), 115-121.

Machel, G., Pires, E. \& Carlsson, G. (2013). The world we want: an end to child marriage. The Lancet, 382(9897), 1005-1006. 21 September 2013. Doi: 10.1016/50140 - 6736(13) 61944-3.

Mahler, H. (1987). The Safe Motherhood Initiative: a call to action. The Lancet, 987, 268-270.

Maine, D. (1987). Prevention of maternal deaths in developing countries: Program options and practical considerations. Paper prepared for the International Safe Motherhood Conference. Nairobi, 1013 February.

McCarthy, J. \& Maine, D. [1992].A framework for analysing the determinants of Maternal Mortality. Studies in Family Planning, 23(1), 23-33.

Population Reference Bureau. Available at: http://www.prb.org

Radkar, A. \& Parasuraman, S. (2007). Maternal deaths in India: an exploration. Economic and Political Weekly, 31.

Rahman, M., DaVanzo, J., Razzaque, A., Ahmed, K. \& Hale, L. (2009). Demographic, Programmatic and Socioeconomic correlates of Maternal Mortality in Metlab, Bangladesh. Paper presented at the annual meeting of the Population Association of America (PAA), Detroit, Michigan. April 30 - May 2, 2009. Pathfinder International. Available at: http://www://pathfinder.org

Raj, A. (2010). When the mother is a child: The impact of child marriage on health and human rights of girls. Archives of Diseases in Childhood, 95, 931-935.

Raj, A. \& Boehmer, U. (2013). Girl child marriage and its association with national rates of HIV, maternal health, and infant mortality across 97 Countries. Violence against Women, 19, 536-551. DOI: 10.1177/1077801213487747. 22 May 2013. 
Rosenfield, A. \& Maine, D. (1985). Maternal mortality - a neglected tragedy: where is the M in MCH? The Lancet, 2(8), 446, 83-85.

Ronsman C. \& Graham, W. J. (2006). Maternal mortality: who, when, where and why? The Lancet, 368(9542), 1189-1200.

Royston, E. \& Armstrong, S, (1989). Preventing Maternal Deaths. Geneva: WHO.

Singh, S. \& Darroch, J. (2012). Adding it up: Costs and benefits of contraceptive services. Estimates for 2012.Guttmacher Institute.

United Nations (UN). (2000). Indicators for Monitoring the Millennium Development Goals, United Nations: New York.

UN. (2013a). Post-2015 Development Agenda. Report of the High Level Panel of Eminent Persons on the Post-2015 Development Agenda. New York: UN.

UN. (2013b). The life of dignity for all: accelerating progress towards the Millennium Development Goals and advancing the United Nations development agenda beyond 2015. Report of the SecretaryGeneral. 68 ${ }^{\text {th }}$ session. New York: UN.

United Nations Children's Fund (UNICEF). (2001). Early marriage: Child spouses. New York: UNICEF.

UNICEF. (2005). Early marriage: A harmful traditional practice. A statistical exploration. New York: UNICEF.

UNICEF. (2013). The state of the world's children 2013: Children with disabilities. New York: UNICEF.

UNDP. (2013). Human Development Report 2013: The rise of the South - Human progress in a diverse World. Available at: http://www./hdr.undp.org

United Nations Population Fund (UNFPA). [2003]. State of the World Population 2003: Making 1 billion count: Investing in adolescent's health and rights. New York: UNFPA.

UNFPA. (2009). The Maternal Health Thematic Fund Annual Report. New York: UNFPA.

UNFPA. (2012). Marrying too young. End Child Marriage. New York: UNFPA.

UNFPA. (2012). State of the World Population: By Choice, Not By Chance. New York: UNFPA.

Walker, G. J. A., Mccaw, A., Ashley, D. C. \& Bernard, G. W. (1985). Maternal Mortality in Jamaica: A confidential inquiry into all maternal deaths in Jamaica 1981-1983. Paper presented at WHO Interregional Meeting on the Prevention of Maternal Mortality, Geneva, 11-15 November.

Winikoff, B., I Sivin, I. \& Coyaji, K. T. (1987). Safety, Efficacy and Acceptability of Medical Abortion in China, Cuba and India: A Comparative Trial of Mifepristone- Misoprostol versus Surgical Abortion. AMJ Obstet Gynecol, 176, 431-437.

World Health Organization (WHO). (1977). Manual of the International Statistical Classification of Diseases, Injuries and Causes of Death. Geneva: WHO.

WHO. (2009). Today's evidence Tomorrow's agenda. Geneva: WHO.

WHO. (2013). Available at: http

WHO, UNICEF, UNFPA, World Bank. (2010). Trends in Maternal Mortality: 1990 to 2008. Estimates developed by WHO, UNICEF, UNFPA and the World Bank. Geneva: WHO.

World Bank Data. Available at: http://data.worldbank.org/topic. 